\title{
Gonadoreline Hormone Ameliorate the Deleterious Effects Of Nicotine On Uterine Performances During Pregnancy: Animal Model Study
}

\author{
Hayder M. Al-kuraishy ${ }^{1}$, Salah A.Al-weendy ${ }^{2}$, ALI.I Al-gareeb ${ }^{3}$, Iman N.A.Al-bajajy ${ }^{4}$, \\ Ali K.Al-buhadilly ${ }^{5}$, Ammar A.Al-hafeth ${ }^{6}$ \\ ${ }^{1}$ Lecturer in Department of Pharmacology and medicine, College of Medicine, Al-Mustansiriya University,P.O. Box 14132, \\ Baghdad, Iraq. \\ ${ }^{2}$ Lecturer in Department of microbiology, Lecturer in Department of Pharmacology, College of Medicine, Al-Mustansiriya \\ University, P.O. Box 14132, Baghdad, Iraq. \\ ${ }^{3}$ Lecturer in Department of Pharmacology, College of Medicine, Al-Mustansiriya University, P.O. Box 14132, Baghdad, Iraq. \\ ${ }^{4}$ Assist lecturer in Department of Pharmacology, College of Medicine, Al-Mustansiriya University, P.O. Box 14132, Baghdad, Iraq. \\ ${ }^{5}$ Assist lecturer in Department of Pharmacology, College of Medicine, Al-Mustansiriya University, P.O. Box 14132, Baghdad, Iraq. \\ ${ }^{6}$ Assist lecturer in Department of Pharmacology, College of Medicine, Al-Mustansiriya University, P.O. Box 14132, Baghdad, Iraq.
}

\begin{abstract}
This study was conducted on females rabbits of Newzealand white rabbit which was as an experimental model.The aim of this study is to elucidate the the effects of tobacco smoke exposures at doses 10 cigarettes and 20 cigaettes /day alone and in combination with of gonadoreline hormone subcutaneously; which was exposed daily from first day of gestation until the time of delivery .then showing the effects of litter boy weight in correlation with pregnancy period.
\end{abstract}

Results of this study showed that exposures to cigarette smoke alone in different doses reduced the litter body and pregnancy period consequentially $(\mathrm{p}<0.05)$. while exposures to cigarette smoke under effects of gonadoreline insignificantly affects these parameters $(\mathrm{p}>0.05)$.

Keyword: Gonadoreline, Nicotine, Uterine Performances, Pregnancy and Animale Model .

\section{Introduction}

Women who smoke are more likely to be infertile or take longer interlude to conceive than who do not smoke ${ }^{(1)}$ In addition ,smoker women are more liable to have an earlier menopause than are non-smokers ${ }^{(2)}$.Increased metabolism of estrogen may not be the whole explanation and smokers have a small increased risk of spontaneous abortion, bleeding during pregnancy and development of various placental abnormalities ${ }^{(3)}$. On the other hand, women who smoke have lower incidence of toxaemia of pregnancy through the advantage of this do not offset the disadvantage of smoking during pregnancy ${ }^{(4)}$. The placenta is heavier in smoking than non-smoking women and its diameter larger, this represent the adaptation to lack of oxygen due to smoking, secondary to raised concentration of circulating carboxyhaemoglobin ${ }^{(5)}$.

The neonate who smoke are approximately $200 \mathrm{~g}$ lighter than those of women who do not smoke ${ }^{(6)}$. They have an increased risk of death in the perinatal peroid which is independent of other variables such as social class, age ,race and extent of antenatal care ${ }^{(7)}$.

Tobacco smoke produced as the chief pharmacologically active constituents in form of carbon monoxide which is rapidly linked with circulating haemoglobin, which may be important as cause of fetal hypoxia ${ }^{(8)}$. Many reports have suggested that the inhalation of tobacco smoke have deleterious effects on the physiology of reproduction and associated with decreased in pregnancy rate, also smoking is associated with infertility of both sexes $^{(9)}$.

Smoke inhalation lead to dose dependent suppression of neural stimuli for luteinizing hormone release and decrease in rate of animal ovulations ${ }^{(10)}$.Animal neonate litter size correlate with smoking exposure during pregnancy ,but not reach to 
significant effects ${ }^{(11)}$.The toxic effects and adverse reaction of tobacco smoke on animal and human birth weight related to toxic substances such as carbon monoxide and nicotine ${ }^{(12)}$. Gonadorelin also called gonadotrophin releasing hormone $(\mathrm{GnRh})$ releases luteinizing hormone $(\mathrm{LH})$ and follicular-stimulating hormone (FSH) from anterior pituitary gland, the intermittent pulsatile administration evoke secretion of gonadotrophin (LH\&FSH) and it used to treat infertility(13).Although, continuous use evoke tachyphylaxis due to down-regulation of its receptor i.e. gonadotrophin release and these fore gonadal secretion are reduced ${ }^{(14)}$.

Therefore; the long acting analogues like buserelin,goserelin,nafaralin,deslorelin and leuproreline are used to suppress androgen secretion in prostatic carcinoma ${ }^{(15)}$.

The aim of this study is to show the effects of smoking on birth weight and pregnancy period in animal alone and when it used with gonadotrophine to explain the beneficial effects of gonadotrophine and this study reflects the effects of tobacco smoke on human being.

\section{Material and Methods}

This study was carried out in Department of Pharmacology, College of Medicine, Almustansiriya University and Department Of Biology, College Of Science, Baghdad University .Baghdad - Iraq, from October to December 2010. It is approved by scientific jury of Department of Pharmacology and licensed by board of medical college.

This experiment was conducted on adults females newzealand white rabbits ; which were weighting approximately 1.5 $2 \mathrm{~kg}$. They were individually housed in optimized plastic cage measuring $(33-40-35 \mathrm{~cm})$; for 16 days before mating to avoid pseudo pregnancy. Then animals were given $110 \mathrm{mg} /$ day of pelleted rabbit diet and water .Seventy two females were divided equally into three groups:(group A) cigarette smoke 10 and $20 \mathrm{cig}$./day alone and group(B) smoke 10 and 20 cig./day with subcutaneously injection of $0.2 \mathrm{ml}$ gonadoreline hormone $(0.1 \mathrm{mg} / \mathrm{ml})$ at one time before mating ; group $(\mathrm{C})$ as control .Four pregnant rabbits were brought to the special boxes were designed to allow for required dose of cigarette smoke exposure which was done at glass box $50-75-70 \mathrm{~cm}$.; and provided with opening of $15 \mathrm{~cm}$ at the top side for ventilation and introducing the tube containing the lit of cigarette. The animals were exposed for 5-7minute(complete burning time of cigarette) with average nicotine content of $1.1 \mathrm{mg} / \mathrm{cig}$.

All data expressed as mean \pm SD with significant value as $\mathrm{p} \leq 0.05$

\section{Results}

The mean birth weight of litters born to females rabbits who exposed to cigarette smoke at dose 10and 20 cig./day alone showed in tables (1)and (2). from beginning to end injection of gonadoreline hormone; there is a significant $\mathrm{s}$ differences $(\mathrm{p}<0.01)$ appeared between the three groups . While 95\% confidence intervals showed that the major depression appeared and occurred in the cigarette smoke group at dose 10 and 20cig./day(30.35 \pm 1.3 and28.25 \pm 0.85 ); while the cigarette smoke plus gonadoreline hormone showed less depression when compared with control. An attractive results of the litter size in the control was higher than other groups at dose of 10cig/day and 20cig/day for smoke alone;and smoking with gonadoreline hormone ,nonetheless ; the differences were significant $(\mathrm{p}<0.05)$. The mean pregnancy period showed a significant differences $(\mathrm{p}<0.05)$ at dose 10 and 20cig./day and smoking with gonadoreline hormones as compared with the control values. They ranked 27day with cigarette smoke alone and 29day with gonadoreline and 30day with the control. 


\begin{tabular}{|c|c|c|c|}
\hline Control & $\begin{array}{l}\text { Cig.smoke } \\
\text { gonadoreline }\end{array}$ & Cig.smoke alone & Parameters \\
\hline $\begin{array}{l}35.50 \pm 1.15 \\
5.50 \pm 0.92 \\
30.75 \pm 0.53\end{array}$ & $\begin{array}{l}30.75 \pm 0.85^{*} \\
4.82 \pm 1.25^{*} \\
29.25 \pm 0.94^{*}\end{array}$ & $\begin{array}{l}30.35 \pm 1.3 \\
4.65 \pm 1.5 \\
29.16 \pm 0.80\end{array}$ & $\begin{array}{l}\text { Birth weight } \\
\text { Litter size } \\
\text { Pregnancyperiod }\end{array}$ \\
\hline
\end{tabular}

Table (1): The effects of cigarette smoke10 cig./day and gonadoreline on pregnancy of females rabbits.

\begin{tabular}{l|ll|l}
\hline Control & $\begin{array}{l}\text { Cig.smoke } \\
\text { gonadoreline }\end{array}$ & and Cig.smoke & Parameters \\
\hline $36.50 \pm 0.94$ & $29.88 \pm 2.32^{*}$ & $28.24 \pm 1.8$ & Birth weight \\
$5.00 \pm 0.41$ & $4.25 \pm 0.86^{*}$ & $4.50 \pm 0.29$ & Litter size \\
$30.75 \pm 0.25$ & $29.50 \pm 0.29 *$ & $28.25 \pm 0.85$ & Pregnancy period \\
& & & \\
$* \mathrm{p}<0.05$ & & & \\
\hline
\end{tabular}

Table (2): The effects of cigarette smoke20cig. /day and gonadoreline on pregnancy of females rabbits.

\section{Discussion}

The present study cleared out that the main depression in pregnancy parameters occurred in cigarette smoke group in different doses but the smoking with gonadoreline showed less depression as compared with control. Moreover; the present study showed that the exposure of pregnant rabbit to cigarette smoke alone and with gonadoreline hormone at doses 10 cig. Iday and 20 cig. Iday reduce the fetal weight significantly this coincide with reduction in fetal weight of mice exposed to $5-10 \mathrm{mg}$ nicotine $/ \mathrm{kg}$ from 6-13 day of gestation ${ }^{(16)}$. This reduction in fetal body weight may due to uterine vasoconstriction or and fetal hypoxia ${ }^{(17)}$.

A definite and well-established relationship between smoking and low birth weight defined as birth weight less than $2500 \mathrm{~g}$ ,in general the average reduction in birth weight seen in smoking women is $200 \mathrm{~g}$,this result in doubling of the incidence of low birth weight infant, also the risk and magnitude of low birth weight is related to number of cigarettes smoking during pregnancy, the critical period during which smoking exert its deleterious influence has not been determined ,but it has been shown that if women cease smoking during pregnancy the neonate weight will be comparable to a non-smoker ${ }^{(18)}$.

The precise and accurate mechanism for decreased birth weight is still unclear but at the present, there is evidence that smokers do not consume fewer calories or have less weight gain during pregnancy so it has been concluded that the decrease in birth weight seen in infants of smoking is not due to nutritional factors ${ }^{(19)}$. Anthropometric studies comparing the differences in body composition in infants of women who smoke with those non-smokers have found a decrease in the fatfree mass ${ }^{(20)}$. Deliberately, weight and length were decrease in the infant of smokers, but no differences in skin fold and limb circumference measurements were seen .It is unknown whether the physiological effects of smoking on fetal growth are due to vasoconstriction or decreased oxygen availability or due to carbon monoxide and formation of carboy- 
hemoglobin ${ }^{(21)}$.Systemic nicotine infusion decrease uterine blood flow and increase uterine vascular resistance and that these effects can blocked by pretreatment with $\alpha$-adrenoceptore blockers phentolamine ${ }^{(22)}$. But there is not acute effect of nicotine on $\alpha$-adrenoceptor mediated contraction of pregnant uterine arteries in vitro ${ }^{(23)}$ Also, direct local infusion of nicotine into uterine artery showed no sound effects on uterine blood flow ${ }^{(24)}$,but chronic nicotine exposure has been shown to cause mitogenic and cytotoxic effects in both smooth muscle cell and endothelial cell in culture at concentration seen in the plasma of habitual smokers ${ }^{(25)}$.

Also, chronic nicotine administration lead to inhibition of endothelial nitric oxide synthase (eNOS) that mediate the uterine vasoconstriction and inhibition of calcium ionophore A23187-induced relaxation of uterine vessels by increase the nitric oxide release $^{(26)}$.The mechanism by which nicotine affects eNOS expression are not fully understood at present because, nicotine can cross cell membrane, it is possible that nicotine can directly regulate eNOS expression .Indeed, previous studies have demonstrated that nicotine and its metabolites produce significantly decreased in the eNOS ,mRNA and protein levels, resulting in ion paired endothelial damage in the uterine artery ${ }^{(27)}$.

Nicotine is possibly the key physiologically active component of tobacco smoke and is quickly absorbed from the respiratory tract of smokers. Even though it has often been tacit that pulmonary absorption of nicotine from inhaled cigarette smoke is faster than by other routes the lung appears to serve up as a reservoir for nicotine, which slows its entry into the arterial circulation ${ }^{(28)}$. This implies that quite than all of the nicotine inhaled in each puff being absorbed in a few seconds, it may require 30-60 seconds or longer for the nicotine to be fascinated. Formerly in the maternal circulation, nicotine willingly crosses the placenta and enters the fetal circulation it can enter the amniotic fluid and from there it can be absorbed by means of the skin of the fetus ${ }^{(29)}$.

The consent of nicotine and cotinine, the main product of nicotine metabolism, is augmented in pregnant women ${ }^{(30)}$. This can be attributed to an increase in liver blood flow and an increased enzymatic breakdown of nicotine and cotinine in the mother. Because the enzymatic protection mechanisms of the fetus are not well residential, the metabolism of nicotine in the fetal liver is sluggish and a longer half-life of nicotine in the fetus can be predictable ${ }^{(31)}$. This is established by the advanced concentrations of nicotine in fetal tissue compared to maternal blood levels ${ }^{(32)}$. Accordingly the cells of the growing lung and other organs are showing to higher concentrations of nicotine for longer periods of time and therefore to the adverse effects of nicotine on cell veracity. This is important as nicotine is genotoxic ${ }^{(33)}$ and induces the release of oxidants .Because rapidly separating cells are more susceptible to the effects of strange substances such as nicotine it is believable that nicotine exposure during gestation and early postnatal life via maternal milk may hinder with expansion and development. This can be achieved in two ways: by having a straight effect on cells by dropping the nutrient supply to the fetus during gestation and lactation ${ }^{(34)}$.

It has been revealed that maternal smoking is linked with increased levels of oxidative stress markers in the mother and offspring ${ }^{(35)}$. There is also persuasive in vivo and in vitro evidence suggesting that exposure to nicotine results in oxidative stress in fetal, neonatal and adult tissues . Reactive oxygen species (ROS) aim mitochondria, and mitochondrial DNA has been shown to be more sensitive to the harmful effects of ROS than nuclear DNA ${ }^{(36)}$. In adding together, the electron transport chain enzyme complexes in the inner membrane of the mitochondria are extremely sensitive to ROS inactivation .

In addition to inducing overproduction of oxidants, nicotine exposure results in a decrease in the activity of SOD and catalase. The increase in ROS levels, together with a decrease in the activities of enzymes with antioxidant function, results in an imbalance in the oxidant/antioxidant capacity ${ }^{(37,38)}$.

It is conceivable that the increased levels of nicotine-induced ROS in the fetus and suckling neonate as a consequence of maternal smoking or NRT will result in not only mitochondrial DNA damage but also injure of nuclear DNA. It is consequently liable that nicotine and ROS will consequence in a alter in the capability of the mitochondria to deliver energy and to contribute in homeostatic mechanisms and in changing the "program" that control growth, tissue maintenance, aging and cellular metabolism, It is supposed that the early stage of organogenesis is the most susceptible stage of embryogenesis to environmental invective ${ }^{(39)}$.Altering the in utero environment during early organogenesis may weaken the process and in this way modify the structure and function of organs in the long term. Tobacco smoke introduces more than 4,000 chemicals into the circulation. A lot of of these chemicals, including nicotine, cross the placental barrier and enter the blood of the developing embryo and fetus. They can also enter the amniotic fluid and in this mode alter the environment inside which the embryo and fetus grows and develops. Nicotine is a major teratogenic constituent of tobacco smoke which can disturb embryogenesis. Studies in rats have shown that nicotine can encourage embryonic abnormalities, such as neural tube malformations, before and during the early stages of organogenesis, in a concentration-dependent style ${ }^{(40)}$. The nicotineinduced embryonic malformations were associated with increases in planned cell death in embryos. Nicotine can also cause 
cell death by increasing intracellular calcium levels and oxidative stress in the embryo. Relentless embryonic malformation may result in embryonic demise and is associated with higher spontaneous abortion and miscarriage in humans these malformations are consideration to be caused by the nicotine-induced overproduction of ROS ${ }^{(41)}$.

In attempts to embryonic mortality and improve reproductive performance in rat and cattle, progesterone supplementation has been employed during early pregnancy ${ }^{(42)}$ Another loom in reducing embryo loss during early pregnancy has been the administration of exogenous gonadoreline ${ }^{(43)}$. The effects of synthetic $(\mathrm{GnRH})$ on conception rate in dairy cows when injected at the time of artificial insemination and between 11-13 days after insemination improve the reproductive performance ${ }^{(44)}$.Treatment with GnRH and its analogne cause acute secretion of LH \& FSH in peripheral blood this lead to induction of alteration in the corpus luteum ${ }^{(45)}$.Also,gonadoreline improve uterine blood flow by inhibition of prostaglandin $\mathrm{F}_{2}-\alpha$ that cause uterine vasoconstriction and decrease oxytocin receptor so decrease the effects of oxytocin that cause uterine contraction and increase in uterine vascular resistance. ${ }^{(46)}$ Moreover, gonadoreline decrease estrogen level which responsible for oxytocin receptor synthesis. ${ }^{(47)}$

Additionally,chemical components of tobacco smoke may induce alkylation of DNA both in the oocyte and sperm which consequential to abnormal cytogenesis embryo ${ }^{(48,49,50)}$.

Therefore, gonadoerline down-scale the effects of tobacco smoke and nicotine on uterine vasculature and attenuate the toxic effect on embryo which per se explaine the insignificant effect of tobacco smoke when combined with cyclical gonadoerline injection.

\section{References}

1- $\quad$ Grunbrg N. Smoking cessation X weight gain .New England Journal of Medicine.1991;324-25

2- $\quad$ Henningfield J. Nicotine medication for smoking cessation. New England Journal of Medicine.1995;333-35

3- $\quad$ Nutt D. Addiction and brain mechanism.Lancat. 2001; 457-8

4- $\quad$ Peto R. Smoking and death :the past 40 years and next 40 years. By M Jou.2000;309-11

5- $\quad$ Doll R. et al Mortality in relation to smoking .B M J 2001;301-3

6- $\quad$ Green A., Goodwin M. Nicotine and ectevay .BMJ,1999;312-1493

7- $\quad$ Kaplan N. Nicotin \& pregnancy. Lanat. 1995; 345: 1588

8- Long L. Carbon monoxide in the pregnant women and felis and its exchange across placenta.Ann.NY Acad.Sci.1970;174:313

9- Butler N.,Soldestein H.,Ross E. Cigarrete smoking in pregnancy and its influence on birth weight and perinateal mortality .BMJ 1972;127-130

10- Mulachy R. and Martin F.Placental changes and maternal weight in smoking and non-smoking Motrin.AmJ.Obst.1989;(100):170-4

11- Yenug C. Leuny C. and Lee F. Alleviation of cigarette induced intraciterine growth retardation by chines herb.1989;17(4):247-31

12- Paulson R.,Shanefeid J. Effects of smokers tobacco on development of CD-1 mouse fetus teratogencorcinogen.Mutagen MJ.1988;8:81-93

13- Bagatell C. Bremner W. Androgen and gonadoreline in menapoaes and abuses. New England Journal of Medicine,2003;2(1):334-36

14- Healy D. et al Female infertility: cause and treatment:Lancent 2001;2(3):1539-41

15- Vessey M. et al Mortality among oral contraceptive uses:20 years follow up of women in cohort study.BMJ.1999;299-101

16- Paulson R.,Shanefeid J. The effect of tobacco smoke on the fetal development.BMJ.1999;20:66-7

17- Nash J. Embrypathic risk of cigaretle smoke.Exp.Pathol.1991;33:56-3

18- Li C.,Windsor R.,Perkins L.et al The impaction infant birth weight and gessation and age of cotinine-validaled smocking reduction during pregnancy. JAMA 2003;269:1519-24

19- Lindsay C.A ,Thomas A.J ,Catalano P.M .The effects of smoking tobacco on neonates body composition during pregnancy .Teratology 1999;34:65-71

20- Shino P.H. Congenital malformation and maternal smoking .Teratologx;2001;11:21-2

21- Olds D. intellectual impairmution children of women who smoke cigarette during pregnancy. Pediatric 2001;93:221-3 
22- Nelson S.,Steinsland O.,Wang Y. Increased nitricoxide synthese activity and expression in human uterine artery during pregnancy . Cir.Res2000;87:406-411

23- Pittilo R. Cigarette smoking and endothelial injury -are view Adv Exp Med Biol.2003;317:61-7

24- Powell J. Vassscular damage from smoking: disease mechanism and the arterial wall. Vas Med.2004;3:21-28

25- Resnik R.,Brink G. and Wikes M. Catecholamia mediated reduction in uterine blood flow after nicotin infusion .J Clin Invest 2003;63:1133-1136

26- Senser G.,Kpucu G.,Paskaloglu K.,Ayanoglu-Dulger G.,Arbak S.,Erosy Y. and Alican I. Melatonin revere urinary system and aorta damage in the rat due to chonic nicotine administration. $J$ Pharm Pharmacol.2004;56:359-66

27- Xiao D.,Haung X.,Lawrence J.,Yang S.,and Zhang L. Fetal and neonatal nicotine exposure differentially regulate vascular contractility in adult male and female off spring.J Pharmacol Exp Ther.2007;320:654-661.

28- Brewer, B.G.; Roberts, A.M.; Rowell, P.P. Short-term distribution of nicotine in the rat lung. Drug Alcohol Depend. 2004, 57, 193-198.

29- Onuki, M.; Yokoyama, K.; Kimura, K.; Sato, H.; Nordin, R.B.; Naing, L.; Morita, Y.; Sakai, T.; Kobayashi, Y.; Araki, S. Assessment of urinary cotinine as a marker of nicotine absorption from tobacco leaves: A study on tobacco farmers in Malaysia. J. Occup. Health 2003, 45, 140-145.

30- Dempsey, D.A.; Benowitz, N.L. Risks and benefits of nicotine to aid smoking cessation in pregnancy. Drug Saf. 2001, 24, 277-322.

31- Kleinsasser, N.H.; Sassen, A.W.; Semmler, M.P.; Harreus, U.A.; Licht, A.K.; Richter, E. The tobacco alkaloid nicotine demonstrates genotoxicity in human tonsillar tissue and lymphocytes. Toxicol. Sci. 2005, 86, 309-317.

32- Lambers, D.S.; Clark, K.E. The maternal and fetal physiologic effects of nicotine. Semin. Perinatol. 1996, 20, 115-126.

33- Bruin, J.E.; Petre, M.A.; Raha, S.; Morrison, K.M.; Gerstein, H.C.; Holloway, A.C. Fetal and neonatal nicotine exposure in Wistar rats causes progressive pancreatic mitochondrial damage and beta cell dysfunction. PLoS One 2008, 3, e3371.

34- Rehan, V.K.; Wang, Y.; Sugano, S.; Santos, J.; Patel, S.; Sakurai, R.; Boros, L.G.; Lee, W.P.; Torday, J.S. In utero nicotine exposure alters fetal rat lung alveolar type II cell proliferation, differentiation, and metabolism. Am. J. Physiol. Lung Cell Mol. Physiol. 2007, 292, L323-L333.

35- Orhon, F.S.; Ulukol, B.; Kahya, D.; Cengiz, B.; Baskan, S.; Tezcan, S. The influence of maternal smoking on maternal and newborn oxidant and antioxidant status. Eur. J. Pediatr. 2009, 168, 975-981.

36- Droge, W. Free radicals in the physiological control of cell function. Physiol. Rev. 2002, 82, 47-95.

37- Oliveira, E.; Moura, E.G.; Santos-Silva, A.P.; Fagundes, A.T.; Rios, A.S.; Abreu-Villaca, Y.; Nogueira Neto, J.F.; Passos, M.C.; Lisboa, P.C. Short- and long-term effects of maternal nicotine exposure during lactation on body adiposity, lipid profile, and thyroid function of rat offspring. J. Endocrinol. 2009, 202, 397-405.

38- Ornoy, A. Embryonic oxidative stress as a mechanism of teratogenesis with special emphasis on diabetic embryopathy. Reprod. Toxicol. 2007, 24, 31-41.

39- Sekhon, H.S.; Jia, Y.; Raab, R.; Kuryatov, A.; Pankow, J.F.; Whitsett, J.A.; Lindstrom, J.; Spindel, E.R. Prenatal nicotine increases pulmonary alpha7 nicotinic receptor expression and alters fetal lung development in monkeys. J. Clin. Invest. 1999, 103, 637-647.

40- Zhao, Z.; Reece, E.A. Nicotine-induced embryonic malformations mediated by apoptosis from increasing intracellular calcium and oxidative stress. Birth Defects Res. B Dev. Reprod. Toxicol. 2005, 74, 383-391.

41- Wongtrakool, C.; Roser-Page, S.; Rivera, H.N.; Roman, J. Nicotine alters lung branching morphogenesis through the alpha7 nicotinic acetylcholine receptor. Am. J. Physiol. Lung Cell. Mol. Physiol. 2007, 293, L611L618.

42- Newcombe J.R ,Martinez T.A and peters A.R. The effects of the gonadotropine-releasing hormone analogue, busereline on pregnancy rate in horse and ponymars. The riogenobgy2001;55:1619-1631.

43- Cam M.K ,Kuran M., Yildiz S and Sekuk E. Fetal growth and reproductive performance in ewes administration GnRH agoinst.Anim. Reprod.Sci.2002;72:73-82.

44- Singh K. , Maurya S.N and Prasad S. Effects of busereline on pregnancy rate in embryo recipient crossbred cattle. Indian J. Amim.Sci.2003;73-5.

45- Ax R. What cause cows to repeat ? Dairy herd. Management . 2003;Feb:22:11-12.

46- Arikan S.and PamukumT.Role of oxytocine and oxytocin receptor in synthesis of prostaglandin. Universeitesi Vetererines Fatultesi Dergisi 2001;7:123-8.

47- Ghulam A.,Saeed M.A and Bashir I.N. Use of GnRH to improve conception rate in repeated breeder buffaloes during the low breeding season Pakistan Vet.J.2005;22:42-44. 
IOSR Journal of Pharmacy

Vol. 2, Issue 1, Jan-Feb.2012, pp. 065-071

48- Joesbury KA, Edirisinghe WR, Phillips MR, Yovich JL.Evidence that male smoking affects the likelihood of a pregnancy following IVF treatment: application of the modified, cumulative embryo score. Hum Reprod 1998;13:1506-1513.

49- Sun JG, Jurisicova A, Casper RF. Detection of deoxyribonucleic acid fragmentation in human sperm: correlation with fertilization in vitro. Biol Reprod 1997;56:602-607.

50- Rehan, V.K.; Asotra, K.; Torday, J.S. The effects of smoking on the developing lung: Insights from a biologic model for lung development, homeostasis, and repair. Lung 2009, 187, 281-289.

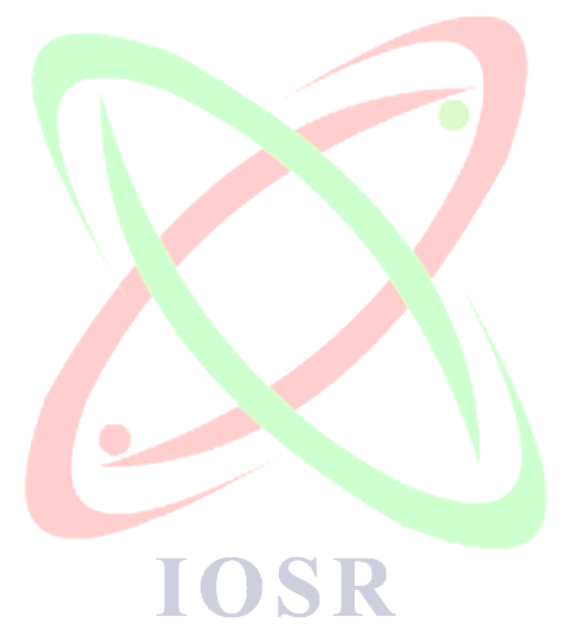

